\title{
Hydrological and hydraulic models for determination of flood-prone and flood inundation areas
}

\author{
Hafzullah Aksoy, Veysel Sadan Ozgur Kirca, Halil Ibrahim Burgan, and Dorukhan Kellecioglu \\ Department of Civil Engineering, Hydraulics Division, Istanbul Technical University, Istanbul, 34469, Turkey \\ Correspondence to: Hafzullah Aksoy (haksoy@itu.edu.tr) \\ Published: 12 May 2016
}

\begin{abstract}
Geographic Information Systems (GIS) are widely used in most studies on water resources. Especially, when the topography and geomorphology of study area are considered, GIS can ease the work load. Detailed data should be used in this kind of studies. Because of, either the complication of the models or the requirement of highly detailed data, model outputs can be obtained fast only with a good optimization. The aim in this study, firstly, is to determine flood-prone areas in a watershed by using a hydrological model considering two wetness indexes; the topographical wetness index, and the SAGA (System for Automated Geoscientific Analyses) wetness index. The wetness indexes were obtained in the Quantum GIS (QGIS) software by using the Digital Elevation Model of the study area. Flood-prone areas are determined by considering the wetness index maps of the watershed. As the second stage of this study, a hydraulic model, HEC-RAS, was executed to determine flood inundation areas under different return period-flood events. River network cross-sections required for this study were derived from highly detailed digital elevation models by QGIS. Also river hydraulic parameters were used in the hydraulic model. Modelling technology used in this study is made of freely available open source softwares. Based on case studies performed on watersheds in Turkey, it is concluded that results of such studies can be used for taking precaution measures against life and monetary losses due to floods in urban areas particularly.
\end{abstract}

\section{Introduction}

Floods are among the most common natural hazards that cause several damages to the properties, injuries and losses of lives. It occurs in different regions all over the World extending to more than $1 / 3$ of the area and $82 \%$ of population (Dilley, 2005). Urbanization and continuous industrial activities trigger the flood and increase the flood damage in flood plains of hydrological watersheds. It is therefore very important to delineate flood-prone areas well in advance to be able to take preventive measures to minimize any damage the flood may cause.

Floods are studied by hydrological, hydraulic and topographical inputs to be analyzed at both spatial and temporal scales. For this aim, numerical models have been developed to calculate flood discharge due to precipitation of a given return period. With the help of the recent modelling technology, flood forecasting becomes more accurate and requires less time than before. Geographical Information Sys- tems (GIS) contributes as an important and very useful tool in this type of hydrological and hydraulic models.

In this study, a regional-scale hydrological model was developed first for the delineation of the flood-prone areas in hydrological watersheds. Two topographical indexes were used in the hydrological model. Once flood prone areas are determined, a hydraulic model was implemented at localscale, for calculating the flow depth and velocity in risky areas along the river for which the freely available HEC-RAS hydraulic model was used. Case study from a watershed in Northern part of Turkey shows the applicability of the models in delineating the flood-prone areas and the flow depth in risky parts of the river in terms of flood risk maps for given return periods of flood discharges. 


\section{Method}

The proposed approach to assess flood hazard has a two-step process, the first step involves the detection and mapping of flood-prone areas by using GIS support and considering the topography of the watershed after which areas at risk are studied with more details by implementing the HEC-RAS hydraulic model to assess flooding parameters (Aksoy et al., 2014). This step is basically a flood susceptibility assessment process and is used to prioritize the flood-prone areas in terms of the importance of the assets at risk. The second step is in fact the flood hazard assessment stage, leading to results which can support decision makers regarding the selection of preventive measures. In the literature, no study exists dealing with the problem as in the way used here other than a case study performed very recently by Samela et al. (2016) for delineation of flood-prone areas in ungauged basins.

\subsection{Regional scale hydrological modelling by wetness indices}

In the first step of regional-scale analysis that accommodates the hydrological model, flood-prone areas in the watershed are identified. For this aim, two softwares, Quantum GIS (QGIS) and System for Automated Geoscientific Analyses GIS (SAGA GIS), fully supported by GIS were used. Both GIS softwares are freely available and user-friendly. The methods to map flood-prone areas at regional scale are based on the Topographic Wetness Index (TWI) approach and its variant, the SAGA WI, respectively.

TWI used in QGIS was suggested by Beven and Kirkby (1979) as

$\mathrm{TWI}=\ln \left(\frac{A_{s}}{\tan \beta}\right)$

where $A_{s}$ is the (upslope) flow accumulation area (or drainage area) per unit contour length (Wilson and Gallant, 2000 ) and $\beta$ is the angle of the slope. TWI has found a wide range of application in hydrology (Moore et al., 1991; Quinn et al., 1995; Sørenson et al., 2006). Although TWI assumes that the soil in the watershed is homogeneous and isotropic as a constraint, it was found that topographical changes become much more important, therefore, the difficulty in this assumption becomes negligible compared to the change in the topography of the watershed. This allows one to use TWI in the hydrological analysis in this study.

The SAGA WI used in SAGA GIS is based on a modified catchment area calculation which does not consider the flow as a very thin film. As a result, it predicts, for cells situated in valley floors with a small vertical distance to a channel, a more realistic and with higher potential soil moisture as compared to TWI. This fact is translated to a wider area calculated as potentially covered with water during a flood event.
The TWI can be effectively used to reveal the flooding susceptibility by mapping the flood prone areas. The procedure to calculate the TWI and the SAGA WI in order to define the susceptibility to flooding (the flood-prone areas) is very straight forward since the selected open source software Quantum GIS (QGIS) incorporates the respective routines built into the SAGA GIS.

\subsection{Local scale hydraulic modelling in HEC-RAS}

The hydraulic analysis is performed to determine hydraulic characteristics of water flow, such as flow depth, flow velocity, forces due to water flowing on a surface or at a hydraulic structure, etc. The aim of this part in this study is to determine the characteristics of flow and potential flooding in streams and areas that have suffered flooding in the past taking into account the precipitation and surface runoff draining from the basin.

Hydraulic modelling and analysis have shown extensive research effort to simulate flood propagation in rivers. This is expressed by numerous 1- and 2-dimensional simulation models including HEC-RAS, Mike11, FLO-2D etc. The outcomes of these models, in riverine flood hazard assessment, include the level of inundation (flood water level), the intersection of the flood level with the terrain (ground surface) to create the flood plain extent, the difference between the flood level and the terrain, which is used to calculate the depth and the flow velocity.

Hydraulic analysis for assessing hydraulic behavior for the needs of this study was implemented with the HEC-RAS software (USACE, 2010) that can be downloaded from the official Hydrologic Engineering Center, River Analysis System (HEC-RAS) web site freely.

\section{Study area and watershed}

As mentioned previously, the pilot implementation of flood hazard assessment includes two phases: a regional implementation and a local implementation. The regional implementation was done in Ikizce watershed located in Samsun and Ordu provinces, the Middle Black Sea region in northern part of Turkey (Fig. 1). The local implementation for the flood hazard assessment was done for the Akçay Creek in the Ikizce watershed. Akçay Creek is located within the Terme district of Samsun, which is $56 \mathrm{~km}$ to the East of the Samsun city center. All rivers including the Akçay Creek are known to be critical in terms of flash floods, causing losses, even casualties in the watershed.

Samsun province exhibits the Northwestern climate of Turkey, which covers the coastal Black Sea area including the Northern faces of the mountains and Northeastern part of Marmara region. The mean annual precipitation in Samsun is $683.2 \mathrm{~mm}$. Maximum precipitation is seen in October, November and December with the values of $88.8,82.5$ and $72.9 \mathrm{~mm}$, respectively. It may be of particular interest 


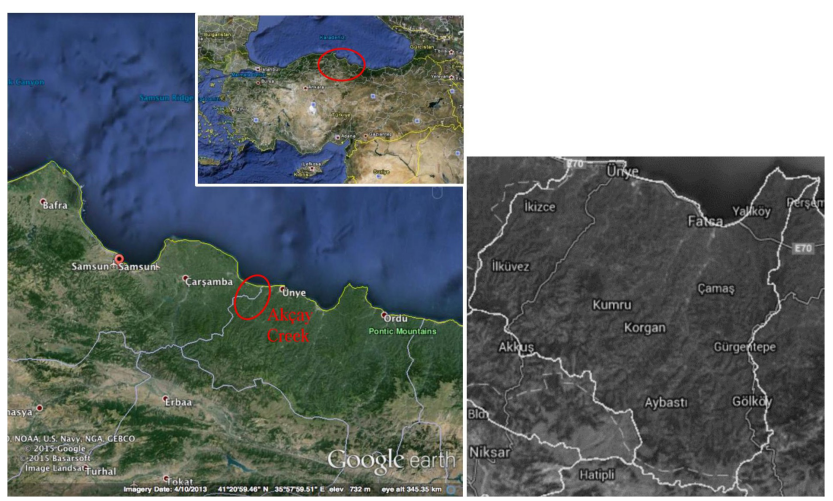

Figure 1. Geographic location and terrain view of Samsun (courtesy of GoogleEarth ${ }^{\circledR}$ ) and Ikizce watershed.

to mention that the maximum daily precipitation recorded in Samsun is $113.2 \mathrm{~mm}$ during 32 years of measurements. The temperature difference between summer and winter is not sparse. Summers are relatively cool whereas winters are relatively warmer in coastal lowlands and colder in higher ground with precipitation of snow. The mean annual temperature is $14.2^{\circ} \mathrm{C}$, with the mean monthly summer temperatures of $23.3,23.2$ and $20.0^{\circ} \mathrm{C}$ in August, July and June, respectively. In the winter, the mean monthly values drop down to $6.6,7.0$ and $7.8^{\circ} \mathrm{C}$ in February, January and March, respectively. Natural plant cover is humid and wide-leaved forest, turning to coniferous trees in higher lands. In the coastal areas along the river banks, there is an intense population of reeds. In the coastal region of Samsun (including Terme) the major type of encountered soil is clayey sand. The mean infiltration capacity of this soil type is measured to be $9 \mathrm{~mm} \mathrm{~h}^{-1}$, a quite low value.

Akçay Creek discharges directly to Black Sea (Fig. 1). The downstream region of the creek is generally covered by agricultural area, as well as industrial facilities. There is an LNG power plant, an ancient bridge and a primary school building in the close vicinity of this zone. The major intercity highway which connects Samsun to Ordu in the East passes across the Akçay Creek with a new bridge (Fig. 2).

\section{Data}

The data for the regional-scale implementation were compiled from the maps. The Ikizce watershed was delineated from the website of Ministry of Forestry and Water Affairs of Turkey http://geodata.ormansu.gov.tr/. For the hydrological model, 1/25000 scale maps were used as the topographical data obtained from Turkish Army General Command of Mapping.

For the local-scale model, cross-sections of the river were produced from 1/500 scale digital maps. For using in the local-scale implementation, the 2, 5, 10, 25, 50, 100 and 500-year return period flood hydrographs of the Akçay Creek

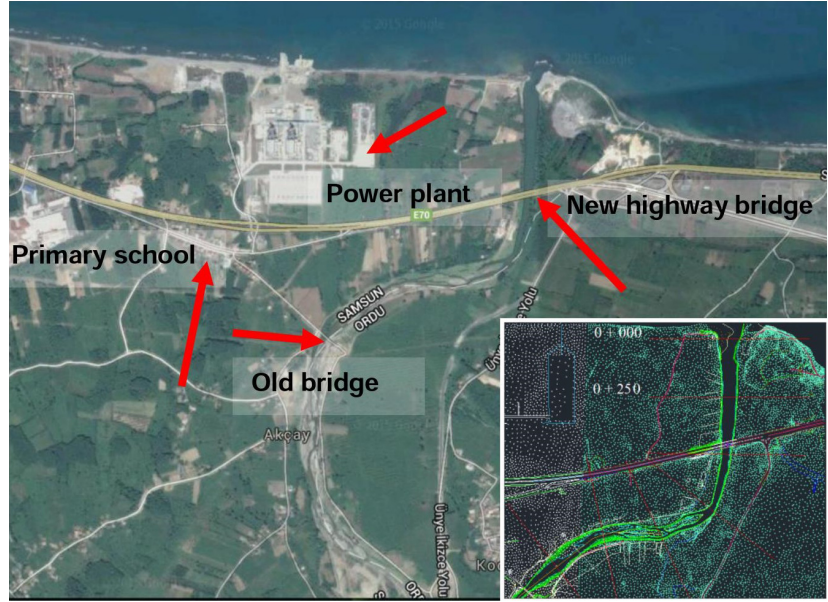

Figure 2. A detailed view of Akçay Creek in Ikizce watershed.

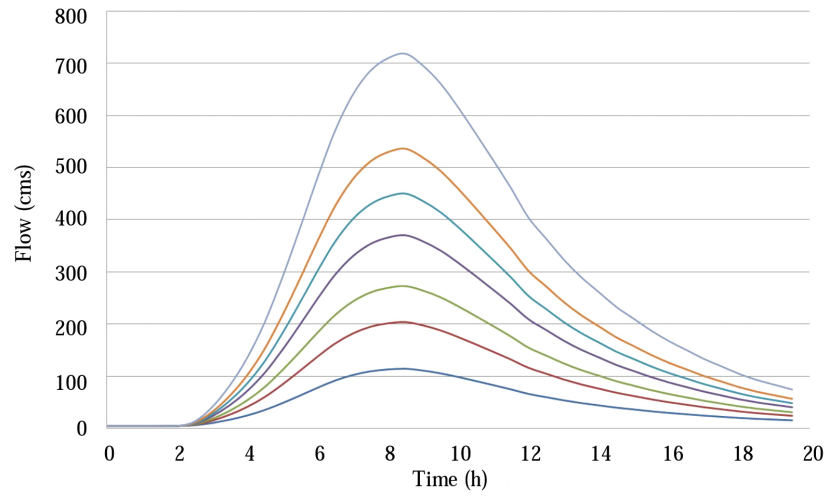

Figure 3. Flood hydrograph in Akcay Creek for 2, 5, 10, 25, 50, 100 and 500-year return periods.

were obtained from State Hydraulic Works (DSI) of Turkey as given in Fig. 3. Peak discharges of the flood hydrographs are tabulated in Table 1. A steady-state flow with the flood discharge is assumed in the hydraulic analysis. Cross sections at every $20 \mathrm{~m}$ longitudinal distance were used to define the flow geometry in HEC-RAS. These cross-sections were extracted from the DEM with a grid resolution of $2 \mathrm{~m}$.

\section{Data availability}

The local-scale maps were made available for implementation of this particular study but not to share with a third party or publicly.

\section{Implementation}

\subsection{Regional-scale implementation}

For the regional scale, the previously explained methodology was used which was implemented in the QGIS and SAGA GIS. For this purpose, the following procedure is applied: 
Table 1. The flood hydrograph of Akçay Creek.

\begin{tabular}{ccccccc}
\hline$Q_{2}$ & $Q_{5}$ & $Q_{10}$ & $Q_{25}$ & $Q_{50}$ & $Q_{100}$ & $Q_{500}$ \\
\hline \multicolumn{7}{c}{$\left(\mathrm{m}^{3} \mathrm{~s}^{-1}\right)$} \\
\hline 109.57 & 199.02 & 267.87 & 365.30 & 445.09 & 531.01 & 713.10 \\
\hline
\end{tabular}

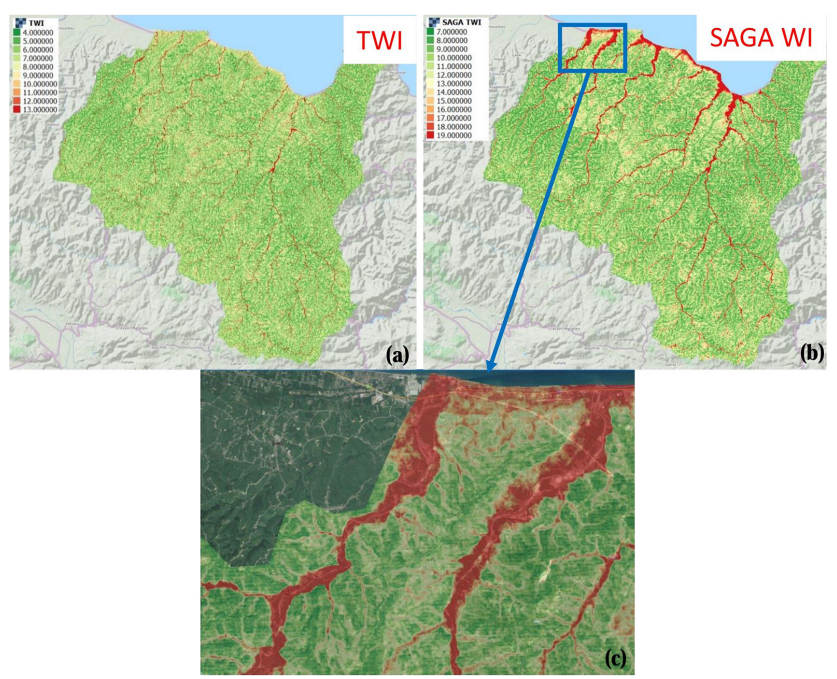

Figure 4. Regional-scale analysis of Ikizce watershed, (a) TWI, (b) SAGA WI; (c) a close-up view of downstream area of Akçay Creek.

- Using the sub-basin templates in http://geodata. ormansu.gov.tr, the DEM files are trimmed into subbasins, such that each file covers a single sub-basin.

- Once the sub-basin DEMs are generated, they are processed with the integrated computational steps using QGIS interface.

- The aspects, unit catchment area, TWI and SAGA WI are calculated.

- These indexes are converted into maps which show the flood-prone areas as the result of regional-scale flood hazard assessment.

Although there is not a strict universal criterion to differentiate the flood-prone areas solely on the isolated values of the aforementioned indexes, the distribution of the indexes across the river basins give very crucial qualitative information about the flood susceptibility of any location of interest within the basin. Figure $4 \mathrm{a}$ and $\mathrm{b}$ shows the TWI and SAGA WI for the Akçay Creek in Ikizce basin. In Fig. 4c, a close-up view of the SAGA WI is shown.

\subsection{Local-scale implementation}

The area chosen for the local scale flood hazard assessment is the Akçay Creek in the Akçay village, which is located in the border of Samsun and Ordu provinces. In the output of the regional scale flood hazard assessment model, the downstream area of Akçay Creek came out to be a critical flood-prone zone based on wetness indexes in Fig. 4a and b. The close-up view of this location in Fig. 4c shows that the downstream section of the river is the most susceptible zone in the watershed against flooding. Therefore, it was decided to model this region at local scale by means of the 1-D hydraulic modelling using the HEC-RAS software.

As stated above, for the hydraulic analysis, cross-sections of the river were produced from 1/500 scale-digital maps at every $20 \mathrm{~m}$ along the river. The HEC-RAS model was run for the 2-, 5-, 10-, 25-, 50-, and 100-year return period flood hydrographs under steady-state subcritical flow conditions.

Results are given in Fig. 5 for floods with the above mentioned return periods. As can be seen, when the peak discharge exceeds the 10 year-return period extreme value, the creek tends to overflow from its bed. This draws a parallel picture with what happens in reality. Especially at the last $300 \mathrm{~m}$ of the creek (i.e. downstream of the highway bridge, see Fig. 2) the inundation area is considerably high. In the modelling, it was seen that the highway bridge is flooded with return periods higher than 100 years. A flood recorded in July 2012 was found to be roughly the 85 year-return period flood in the watershed (Onoz et al., 2012). If the storm surge that rises the sea level at the downstream (say, at the order of $0.5-1 \mathrm{~m}$ ) is taken into account, the observation in July 2012 comes to an agreement with the model results.

\section{Conclusions}

Following conclusions can be drawn from the regional scale and local scale flood hazard assessment modelling studies implemented:

- The proposed regional scale methodology is simple, easy and inexpensive (free software and minimum amount of data requirement); yet it is very effective in terms of pinpointing the flood-prone locations in hydrological watersheds.

- 1/25000 scale maps are very convenient for the application of the regional model to yield high resolution results. However, experience shows that even the ASTER DEM maps (freely downloadable from http://www.jspacesystems.or.jp/ersdac/GDEM/E/ index.html) can yield satisfactory results on revealing flood-prone areas.

- An additional point, based on several case studies performed by Ermiş (2015) (not covered in this study), is that the regional scale flood hazard assessment model can be operated both with small basins (in size of a few hundred $\mathrm{km}^{2}$ ) and relatively large basins (in size of a few thousand $\mathrm{km}^{2}$ ). In any case, operating with smaller 

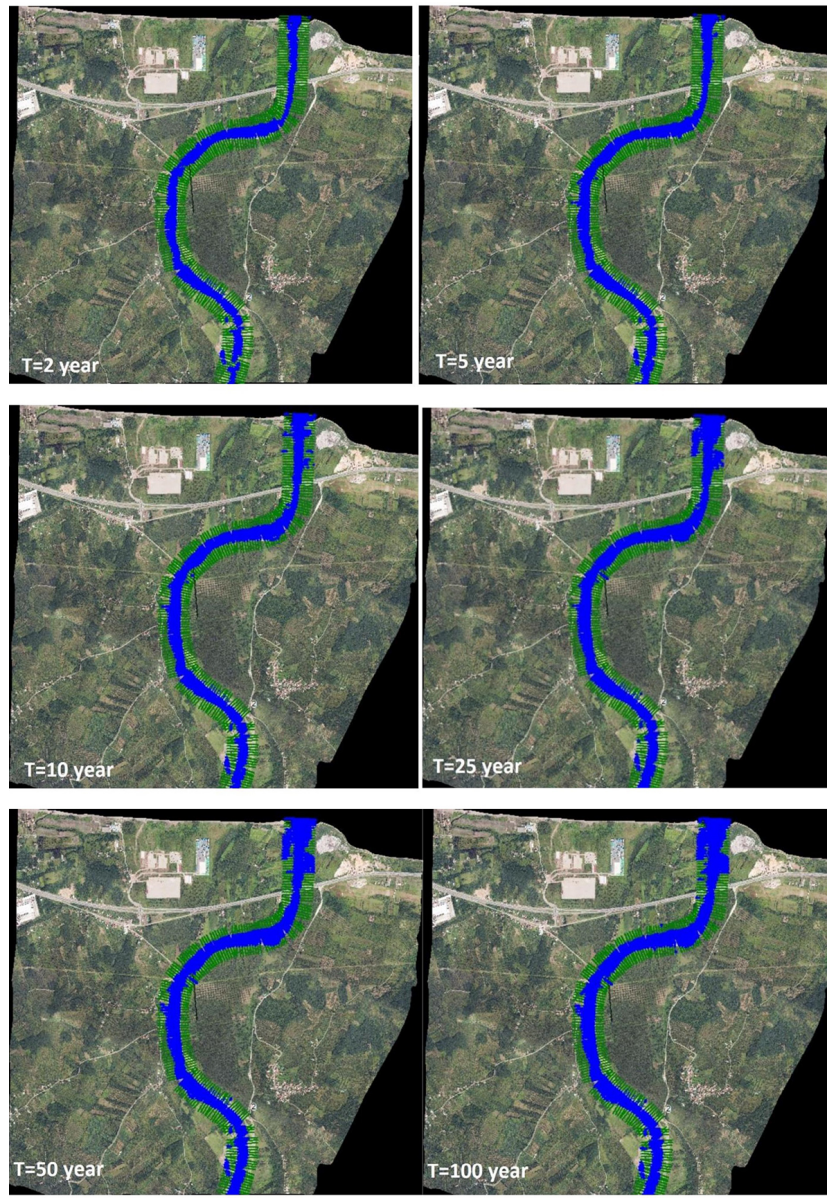

Figure 5. Results of local scale hydraulic model for different return period floods.

basins may be more practical since the precision of the results would be presumably higher.

- The local scale flood hazard assessment model (the 1D hydraulic model) implemented by use of HEC-RAS yielded precise results for the probable flood inundation areas for different return periods of flood occurrences.

- As a specific result of the case study here, it was seen that the Akçay Creek overflows its bed for return periods larger than 10 years and the events tend to become more catastrophic for extreme events larger than 100 year-return period, since the highway bridge is inundated leading to further flooding upstream.

It should additionally be noted that any possible sea level rise in Black Sea (i.e. due to storm surge, wind or wave setup) was not accounted for in the flood modelling. Such rises in the sea level are likely to increase the flooded areas due to the downstream-controlled flow regime in the river.
Acknowledgements. This study is based on the research project "A Scientific Network for Earthquake, Landslide and Flood Hazard Prevention - SciNetNatHazPrev" (no. TR11C1.01-02/309) which is implemented under the Black Sea Basin Joint Operational Program, co-funded by the European Union and national funds of the participating countries.

\section{References}

Aksoy, H., Kirca, V. S. O., and Papatheodorou, K.: Flood hazard assessment and modelling practices in Turkey, Proceedings of the Mediterranean Meeting on "Monitoring, modelling and early warning of extreme events triggered by heavy rainfalls", University of Calabria, Cosenza, Italy, 26-28 June 2014, 205-214, 2014.

Beven, K. J. and Kirkby, M. J.: A physically-based variable contributing area model of basin hydrology, Hydrol. Sci. Bull., 24, 43-69, 1979.

Dilley, M.: Natural disaster hotspots: A global risk analysis, Vol. 5, World Bank Publications, Washington, DC, 2005.

Ermiş, I. S.: Determination of flood-prone areas with topographic wetness indices in the river basins, Istanbul Technical University, Institute of Science and Technology, Istanbul, June 2015, 65 pp., 2015 (in Turkish).

Moore, I. D., Grayson, R. B., and Ladson, A. R.: Digital terrain modeling: A review of hydrological, geomorphological and biological applications, Hydrol. Process., 5, 3-30, 1991.

Onoz, B., Kabdasli, S, Varol, O.E., Yuce, A., and Bora, O.: Report on assessment of flood characteristics and risks due to Akçay River for OMV Gas \& Power, Technical Report by ITU and CEC, NO. C-1209047, 2012.

Quinn, P., Beven, K., and Lamb, R.: The $\ln (\alpha \mathrm{s} / \tan \beta)$ : how to calculate it and how to use it within the TOPMODEL framework, Hydrol. Process., 9, 161-182, 1995.

Samela, C., Manfreda, S., Paola, F. D., Giugni, M., Sole, A., and Fiorentino, M.: DEM-based approaches for the delineation of flood-prone areas in an ungauged basin in Africa, J. Hydrol. Eng., 21, 06015010, doi:10.1061/(ASCE)HE.19435584.0001272, 2016.

Sørensen, R., Zinko, U., and Seibert, J.: On the calculation of the topographic wetness index: evaluation of different methods based on field observations, Hydrol. Earth Syst. Sci., 10, 101-112, doi:10.5194/hess-10-101-2006, 2006.

USACE: HEC-RAS Users Manual for version 4.1, CPD-68, Davis, CA (downloadable from http://www.hec.usace.army. mil/software/hec-ras/documentation/HEC-RAS_4.1_Users_ Manual.pdf), 2010.

Wilson, J. P. and Gallant, J. C.: Digital terrain analysis. Terrain analysis: Principles and applications, 1-27, 2000. 